\section{Immunohistological study of entheses in spondyloarthropathies: comparison in rheumatoid arthritis and osteoarthritis}

\author{
L Laloux, M-C Voisin, J Allain, N Martin, L Kerboull, X Chevalier, P Claudepierre
}

Abstract

Objective-To determine which inflammatory cell types are present in entheses from patients with spondyloarthropathy (SpA) compared with patients with rheumatoid arthritis (RA) or osteoarthritis (OA).

Methods-Enthesis specimens were obtained during orthopaedic procedures in eight patients with $S p A$, four with $R A$, and three with OA. After decalcification, the lymphocyte subsets (CD3, CD4, CD8, CD20) in the bone marrow component of each enthesis were measured by an immunohistochemical technique.

Results-Oedema and an inflammatory infiltrate were present in all the $\operatorname{SpA}$ specimens, being clearly predominant in the bone marrow component of the entheses. The density of all cell types in the bone marrow was significantly higher in the SpA group than in the two other groups. The cell type CD3+ showed the greatest difference between the SpA and RA groups, being increased fivefold in the groups, being increased fivefold in the
SpA group. Within the SpA group, CD3+ cells were considerably more numerous than CD20+ cells-a difference from the RA group-and the predominant $T$ cells were CD8+.

Conclusion-Persistent oedema with an inflammatory infiltrate composed predominantly of CD8+ cells was noted in the entheses of patients with $\mathrm{SpA}$, being predominant in the bone marrow. These results suggest that CD8+ cells may have a key role in local inflammation in SpAs. (Ann Rheum Dis 2001;60:316-321)

Spondyloarthropathies ( $\mathrm{SpAs}$ ) are a group of arthritides that share many pathogenic, clini$\mathrm{cal}$, and radiological features. ${ }^{1}$ Two major $\mathrm{SpAs}$ are ankylosing spondylitis (AS) and psoriatic arthritis. The pathogenesis of SpAs is still unknown, but a common feature of these diseases is selectivity of the inflammatory process for the entheses- that is, the insertions of ligaments, tendons, and joint capsules into ligaments, tendons, and joint capsules into
bone. $^{2}$ Enthesitis is extremely common in
SpAs, and may be a major culprit in the symptoms and risk of permanent ankylosis characteristic of these conditions. ${ }^{3}$ Despite the importance of enthesitis in the disease process of SpAs, scant information is available on its histopathological features, primarily because of the major ethical and technical problems raised by collection of enthesis specimens from patients with early SpA.

The normal enthesis comprises four easily identifiable histological zones²: zone 1 in which the fibre bundles of the ligament or tendon become more compact just before reaching the bone, zone 2 composed of non-mineralised cartilage, zone 3 composed of mineralised cartilage, and, finally, zone 4 consisting of lamellar bone. ${ }^{2}$ In AS, only the histological features of enthesitis are known: the pathological process seems to involve the subchondral bone, which is the site of an erosive inflammatory infiltrate cells and, sometimes, of polymorphonuclear cells this erosive process is followed by fibrous tissue proliferation, leading to the formation of cartilage and, subsequently, of bone. ${ }^{2}$ To the best of our knowledge no immunohistological data are available on these lesions. Most notably, no tive distribution of the various cell types and lymphocyte subsets. Thus it is not known whether $\mathrm{B}$ or $\mathrm{T}$ lymphocytes predominate in $\mathrm{SpA}$ related enthesitis, or whether the CD4 or the CD8 subset contributes most of the T lymphocytes in the infiltrates. Recent studies of the distributions of these cells in the periphera ynovial membran ${ }^{4}$ and in the sacroiliacjorints did not yield definitive conclusions. Knowledge of which cells predominantly play a part in the local disease process would help to determine which of the current immunological hypotheses for the pathogenesis of SpAs is most likely to be true. ${ }^{6}$

The objective of this study was to use quantitative immunohistological techniques to determine which inflammatory cell types are present in enthesis specimens from patients with SpA during orthopaedic procedures, and to compare the results with those in two other diseases involving different pathogenic rocesses namely, rheumatoid arthritis (RA) processes - namely, rheumatoid arthritis (RA)
and osteoarthritis (OA). 
Table 1 Primary antibodies used in our immunohistochemistry study

\begin{tabular}{llllll}
\hline $\begin{array}{l}\text { Primary } \\
\text { antibodies }\end{array}$ & Manufacturer & Type clone name & Isotype & Dilution * & $\begin{array}{l}\text { Final concentration } \\
\text { (mgll) }\end{array}$ \\
\hline Anti-CD3+ & Dako & Polyclonal & & $1 / 50$ \\
Anti-CD4+ & Novocastra & Monoclonal 1F6 & IgG1 & $1 / 20$ \\
Anti-CD8+ & Dako & Monoclonal C8/1448 & IgG1 & $1 / 2$ & 9 \\
Anti-CD20+ & Dako & Monoclonal L26 & IgG1 & $1 / 50$ & 1.8 \\
Anti-CD68+ & Dako & Monoclonal KP1 & IgG1 & $1 / 30$ & 12 \\
\hline \multirow{2}{*}{ *A 0.05 M Tris buffered saline solution, pH 7.6, was used to dilute the antibodies and was applied }
\end{tabular}
alone as the negative control.

\section{Patients and methods}

PATIENTS

Enthesis specimens were obtained from patients with $\mathrm{SpA}, \mathrm{RA}$, and OA during orthopaedic procedures. The diagnosis was based on European Spondyloarthropathy Study Group (ESSG) criteria for $\mathrm{SpA}^{8}$ and on American College of Rheumatology (formerly, the American Rheumatism Association) criteria for $\mathrm{RA}^{9}$ and OA. ${ }^{10}$ The specimen collection site was selected before surgery so that no changes were induced in the normal surgical procedure. The insertion of the cruciate ligament was removed during total knee replacement and that of the vastus lateralis tendon during total hip replacement. In one patient the insertion of an intervertebral disc was removed during vertebral arthrodesis for pseudoarthrosis, and in another the Achilles tendon insertion was taken during foot amputation for vasculitis. All specimens were prepared by the surgeon (JA or LK) using a standardised procedure. The specimen had to contain both the end of zone 1 and at least $3 \mathrm{~mm}$ of zone 4 , and to have a surface area of at least $5 \times 5 \mathrm{~mm}$. Oral informed consent was obtained from each patient on the day before surgery.

MONOCLONAL ANTIBODY AND

IMMUNOHISTOCHEMICAL STUDIES

After fixation in $10 \%$ buffered formalin, each enthesis was decalcified in nitric acid $(10 \% \mathrm{v} / \mathrm{v}$ for 10 hours), then embedded in paraffin. Fivemicrometre sections were placed on silane coated slides, and air dried overnight to ensure optimal adhesion. Sections for histological analysis were stained with haematoxylin, eosin, and saffron. Sections for immunohistochemical studies were deparaffinised in xylene, rehy drated in increasingly dilute ethanol solutions $(100 \%, 70 \%$, and $50 \%)$, and rinsed in running Table 2 Study patient characteristics and enthesis harvesting site

\begin{tabular}{llllllll}
\hline Patient & Diagnosis & $\begin{array}{l}\text { Age } \\
\text { (years) }\end{array}$ & Sex & $\begin{array}{l}\text { Disease } \\
\text { duration (years) }\end{array}$ & Current treatment & Nature of the surgery & $\begin{array}{l}\text { Enthesis } \\
\text { harvesting site }\end{array}$ \\
\hline 1 & SpA (AS; B27+) & 41 & M & 24 & NSAID & Vertebral arthrodesis & disk \\
2 & SpA (PA; B27+) & 35 & M & 25 & NSAID & TKR & CL \\
3 & SpA (AS; B 27+) & 28 & M & 13 & NSAID & THR & VL \\
4 & SpA (AS; B27+) & 63 & M & 35 & NSAID & TKR & CL \\
5 & SpA (AS; B27+) & 48 & M & 28 & NSAID & THR & VL \\
6 & SpA (AS B27+) & 65 & M & 23 & NSAID, sulfasalazine & THR & VL \\
7 & SpA (AS; B27+) & 29 & M & 10 & NSAID, sulfasalazine & THR & VL \\
8 & SpA (AS; B27+) & 29 & M & 12 & NSAID & THR & VL \\
9 & RA & 82 & F & 6 & Prednisone 30 mg/day & Foot amputation & Achilles tendon \\
10 & RA & 68 & F & 13 & Prednisone 9 mg/day & TKR & CL \\
11 & RA & 45 & F & ND & ND & THR & VL \\
12 & RA & 71 & F & 26 & Prednisone 3 mg/day & TKR & CL \\
13 & OA & 55 & F & ND & NSAID & THR & VL \\
14 & OA & 83 & F & ND & 0 & THR & VL \\
15 & OA & 75 & F & ND & 0 & THR & VL \\
\hline
\end{tabular}

$\mathrm{M}=$ male; $\mathrm{F}=$ female; $\mathrm{THR}=$ total hip replacement; $\mathrm{TKR}=$ total knee replacement; $\mathrm{CL}=$ cruciate ligament; $\mathrm{VL}=$ vastus lateralis; $\mathrm{SpA}=$ spondyloarthropathy; $\mathrm{AS}=$ ankylosing spondylitis; $\mathrm{PsA}=$ psoriatic arthritis; $\mathrm{RA}=$ rheumatoid arthritis; $\mathrm{OA}=$ osteoar-
thritis; $\mathrm{ND}=$ not determined; NSAID = non-steroidal anti-inflammatory drug water. Rehydrated sections were immersed in a retrieval solution $(0.001 \mathrm{M}$ EDTA-NaOH solution, $\mathrm{pH}$ 8), placed in a microwave oven $(750 \mathrm{~W}$ for 10 minutes), and allowed to cool at room temperature. This procedure has been shown to produce a better staining intensity and number of marked cells than other methods. ${ }^{11}$ The sections were then blocked in $5 \%$ buffered non-fat milk (0.05 M Tris buffered saline (TBS), $\mathrm{pH}$ 7.6). The five antibodies listed in table 1 were applied and detected by the alkaline phosphatase anti-alkaline phosphatase (APAAP) technique. Three of these antibodies were commonly used in our laboratory for diagnostic purposes. The anti-CD4+ antibody was tested on lymph node sections according to the same procedures as those used for the study.

The sections were incubated with the primary antibody at a predetermined dilution (table 1) then with antimouse IgG coupled with APAAP complexes (Z259, Dako). Excess antibodies were eliminated by rinsing with buffer (0.05 M TBS, $\mathrm{pH}$ 7.6). The sections were then immersed in a solution containing the APAAP complex (D651, Dako). For the CD4+ and CD8+ antibodies these two steps were done twice to amplify the signal. For the polyclonal anti-CD3+ antibody, an additional step consisting of incubation with antirabbit IgG (obtained in mouse) (MZ37, Dako) was performed to allow anti-CD3+ detection using the APAAP technique. Finally, antigenantibody complexes were detected by determining the effect of alkaline phosphatase on its substrate (naphthol AS phosphate (Sigma)) and a chromogen (fast red TR salt (Sigma)), in the dark. Controls were done without the first antibody or with mouse antibodies matched for isotype at the same concentrations as the primary antibodies (as irrelevant antibodies). This allowed a check to be made that no nonpecific staining occurred.

Each section was examined by two observers, and positive cells were counted in several fields in the bone marrow part, just under the fibrocartilage of the enthesis. A photograticule, which fitted into the eyepieces of the microcope (Lietz Laborlux 12), defined the limits of he $1.2 \mathrm{~mm}^{2}$ fields under $\times 250$ magnification. Successive fields of the medullary area were ite 
examined, excluding overlap. For the evaluation of CD4+ cells, only cells with lymphocyte morphology were included, because CD4 may be expressed by macrophages. The mean (SD)
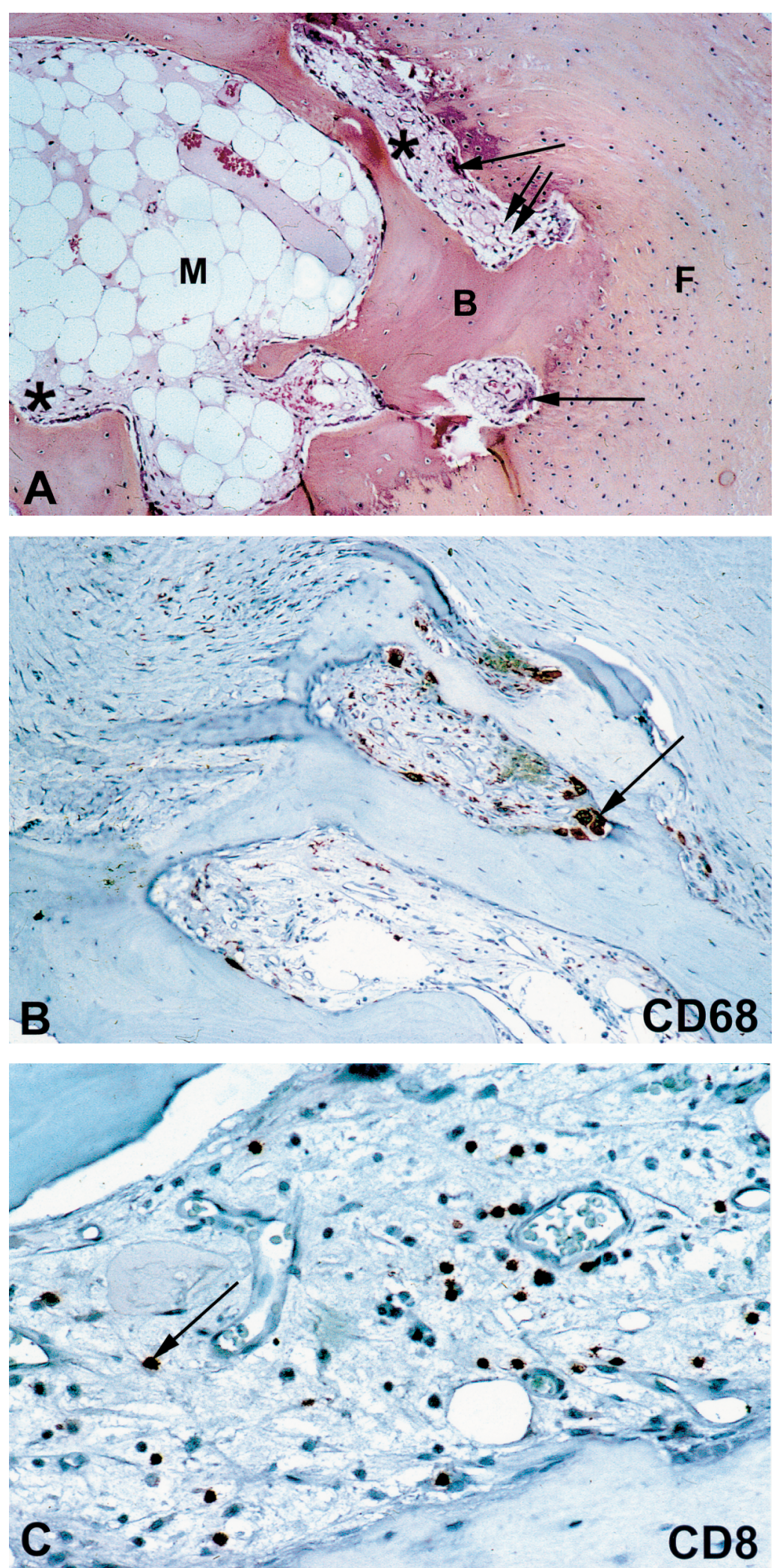

Figure 1 Serial sections of an erosive lesion of a vastus lateralis enthesis in a patient with ankylosing spondylitis (patient 5). (A) Haematoxylin, eosin, and saffron staining. lymphocytic infiltration of the underlying bone marrow. $B=$ bone; $F=$ tendinous fibrosis $M$ $=$ bone marrow; single arrow = osteoclasts; double arrows = lymphocytes; $*=$ oedema.$(B)$ Immunostaining with anti-CD68 antibody. Visualisation of the osteoclasts as CD68+ cells (arrow). (c) Immunostaining with anti-CD8 antibody showing sparse CD8 lymphocytes (arrow) in the bone marrow part of the same enthesis. $(A),(B),(C)$ Original magnification $\times 100$. number of analysed fields was similar for each antibody, ranging from 10.8 (4.8) for CD4+ and 14 (5.1) for CD20+. Each section was scored by counting the mean number of positive cells per field. During the steps of the procedure described above, a number of technical events (see "Results") made some sections unsatisfactory; patients were kept in the study only if at least eight fields could be analysed using all the selected antibodies. For CD68, we did not perform a cell count because this antibody stains both macrophages and osteoclasts in enthesitis.

STATISTICAL ANALYSIS

The mean number of positive cells per field for each antibody was compared between the three groups using the non-parametric KruskalWallis test.

\section{Results}

Some patients could not be included because Some patients could not be included because
of technical difficulties (poor quality of the specimen, difficulties during sectioning, or poor quality of the slide after microwave pretreatment). Of those patients included, eight had an SpA, four had RA, and three had OA. None of the patients with RA or SpA had A. None of the patients with RA or SpA had gives the main patient characteristics and the sites of enthesis collection. Mean age was 42.2 (14.1) years in the SpA group, 66.5 (13.5) years in the RA group, and 69.7 (11.5) years in the OA group. Mean disease duration was 21.2 (8.2) years in the SpA group and 15 (8.3) years in the RA group. All these patients still have an active disease (inflammatory pain from several joints). Seven patients with $\mathrm{SpA}$ fulfilled not only ESSG criteria (required for study inclusion), but also New York criteria for $\mathrm{AS}^{12}$; the exception was patient 2, who had psoriatic arthritis with only mild axial involvement. Antigen B27 was present in all eight patients with SpA.

FINDINGS

Hyperosteoclastic erosive lesions were seen in all eight SpA specimens (patients 1-8 in table 2). Figure 1A shows an example of these erosive lesions. The erosive process was particularly extensive in patients $1-3$. In all the cases of $\mathrm{SpA}$ the inflammation predominated clearly in the bone marrow, where oedema and clearly in the bone marrow, where oedema and an inflammatory cell infiltrate composed thermore, in patients 3-8 the less destructive lesions were associated with cellular hyperplasia and fibrillar aspect of chondroid matrix in the cartilaginous zone (zone 2). Of the four specimens from patients with RA (patients 9-12), only one showed some degree of erosive damage (patient 11); however, the inflammation did not predominate in the bone marrow but rather in the adjacent soft tissue. In specimens 9,10 , and 12 , no significant lesions of the enthesis or adjacent bone marrow were seen. The hyperplastic synovitis typical of RA was The h in the synovial tisue bounding specimens 10 and 12 , and necrotising vasculitis affecting 


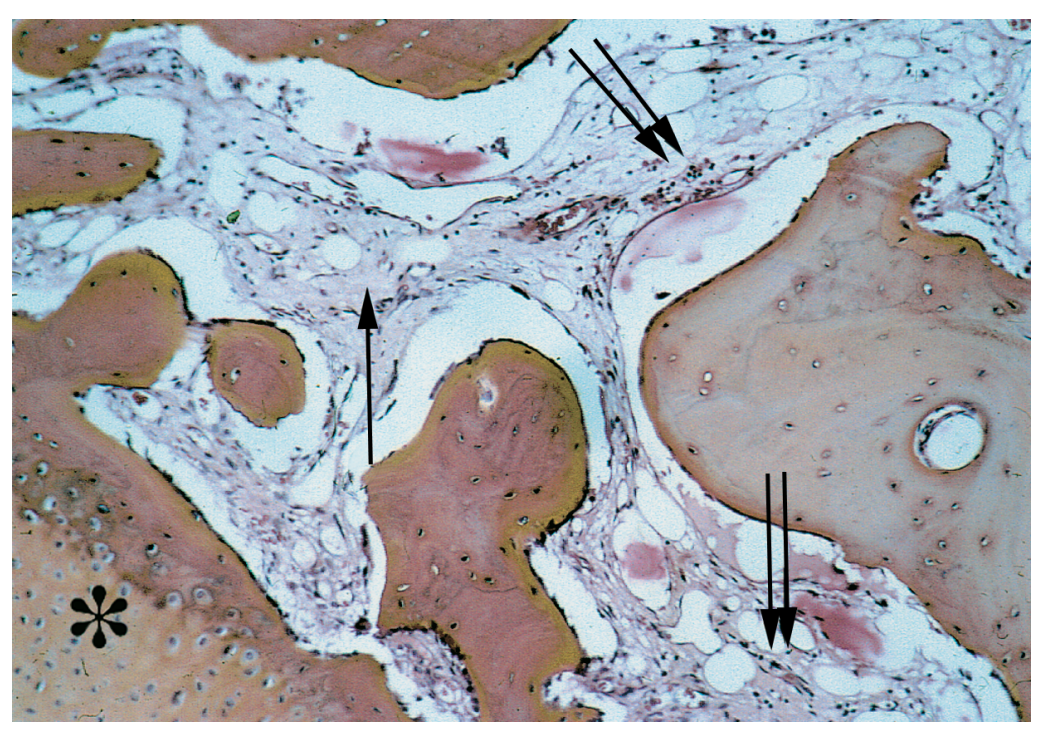

Figure 2 Vastus lateralis enthesis from a patient with ankylosing spondylitis (patient 7). Bone marrow oedema (single arrow) with scattered mononuclear cell infiltrates (double arrows). Hyperplasia of the enthesis fib
staining. Original magnification $\times 100$. Table 3 Counts of cells producing a positive stain with each of the four antibodies in the
spondyloarthropathy $(S p A)$, rheumatoid arthritis $(R A)$, and osteoarthritis (OA) groups

\begin{tabular}{lllll}
\hline & $C D 3^{*} t$ & $C D 4^{*} t$ & $C D 8^{*} t$ & $C D 20^{*} t$ \\
\hline $\mathrm{SpA}$ & $20.6(12.6)$ & $7.7(4.4)$ & $15.5(8.3)$ & $7(3)$ \\
& $18.3(5-46)$ & $8.8(1-13)$ & $14.1(6-31)$ & $7.9(1.7-10.9)$ \\
$\mathrm{RA}$ & $4.1(4)$ & $2(1.9)$ & $2.9(2.5)$ & $4.6(6)$ \\
$\mathrm{OA}$ & $4.4(0-7)$ & $1.7(0-4)$ & $2.9(0-5)$ & $2.3(0.3-13.6)$ \\
& $3.6(4.3)$ & $1.5(2)$ & $2.6(1.4)$ & $0.2(0.4)$ \\
& $1.3(1-8)$ & $1(0-3)$ & $2.9(1-3)$ & $0(0-0.7)$ \\
\hline
\end{tabular}

The figures are the means (SD) and the medians (range) of the mean cell counts in $1.2 \mathrm{~mm}^{2}$ fields groups by the Mann-Whitney test.

the small vessels was noted in specimen 9 . In the OA group, no significant abnormalities were found in any of the three specimens.

IMMUNOHISTOLOGICAL RESULTS

Table 3 reports the bone marrow cellular counts for each antibody (except CD68+) and each patient group. Significant increases in the density of all cell types were seen in the $\mathrm{SpA}$ group compared with the other groups. The CD3+ cells showed the largest difference between the SpA and RA groups, with a fivefold increase in the SpA group. In the SpA group, CD3+ cells were far more numerous than CD20+ cells, whereas this was not the case in the RA group. The CD8+ cells showed larger increases than the CD4+ cells in the SpA group, in which CD8+ counts were more than twice as high as CD4+ counts (table 3). Within the $\mathrm{SpA}$ group, the mean cell counts did not appear to vary with the site of enthesis collection or with the diagnosis-that is, psoriatic arthritis or AS, or sulfasalazine treatment (data not shown).

The CD68+ stain confirmed that hyperosteoclastosis was present in the erosive lesions of the SpA specimens (fig 1B). Furthermore, the inflammatory infiltrates in the bone marrow of the most severely erosive lesions contained some CD68+ cells (macrophages). Although the CD68+ cells were not counted, they seemed less numerous than the CD3+ cells. Figure 3 shows an example of an infiltrate containing the various $\mathrm{T}$ lymphocyte subsets. Figure 1C shows that some CD8+ cells are present in the bone marrow part of the enthesis, right next to the osteoclastic erosions.

\section{Discussion}

To our knowledge, this study provides the first immunohistological data on cell infiltrates in entheses from patients with SpA. An inflammatory infiltrate was present in the enthesis bone marrow of all the SpA specimens, in contrast with RA and OA specimens, and was composed predominantly of CD8+ cells.

A number of technical factors are major stumbling blocks for studies of entheses and can reduce the number of specimens available for immunohistological analysis. Also, the collection of enthesis specimens at an early stage of SpA raises ethical problems. We studied only entheses taken from predetermined sites during a scheduled orthopaedic procedure carried out in patients with longstanding disease. Consequently, we do not know disease. Consequently, we do not know
whether the entheses we examined were whether the entheses we examined were
responsible for symptoms (that is, were the site of active inflammation) at the time they were harvested. However, it is worth pointing out hat the bone marrow component of all the SpA specinens exhibited oedema and an SpAlam gests that inflammation of the bone marrow beneath the enthesis may be a prominent feature of the disease process.

Before discussing the results further, consideration should be given to several factors which might have influenced the data. A possible bias might have been introduced by pooling specimens from different harvesting sites. However, to our knowledge, there are no previous data suggesting that the pathological aspects of the entheses in inflammatory diseases vary with their anatomical site, even though this remain a possibility. But, more importantly, both our histological and immunohistological findings did not seem to be influenced by the type of harvesting site. There is a possibility that drugs, prednisone and disease modifying antirheumatic drugs (DMARDs), affected the cell infiltrate. Three of our patients with RA took prednisone at the time of surgery; none of them was taking a DMARD. The possibility that prednisone may influence the number or type of the entheses of patients with RA remains, even though the entheses are not the primary target of the inflammatory process in RA. Among the patients with SpA, we did not observe a different profile in the two patients who were receiving sulfasalazine treatment, which may suggest that sulfasalazine did not significantly influence the results in the $S p A$ group. We do not know whether disease durathe cellular aspects of enthesitis, and the samples size of our study did not allow an analysis according to this factor. However, a recent study has shown that disease duration has no influence on the histological and immunohistological profiles of synovial tissue of RA or reactive arthritis. ${ }^{13}$ may be thought that disease activity should have an influence on the cellular infiltrate of 
entheses, at least in SpA. However, we cannot confirm this point because all our patients had
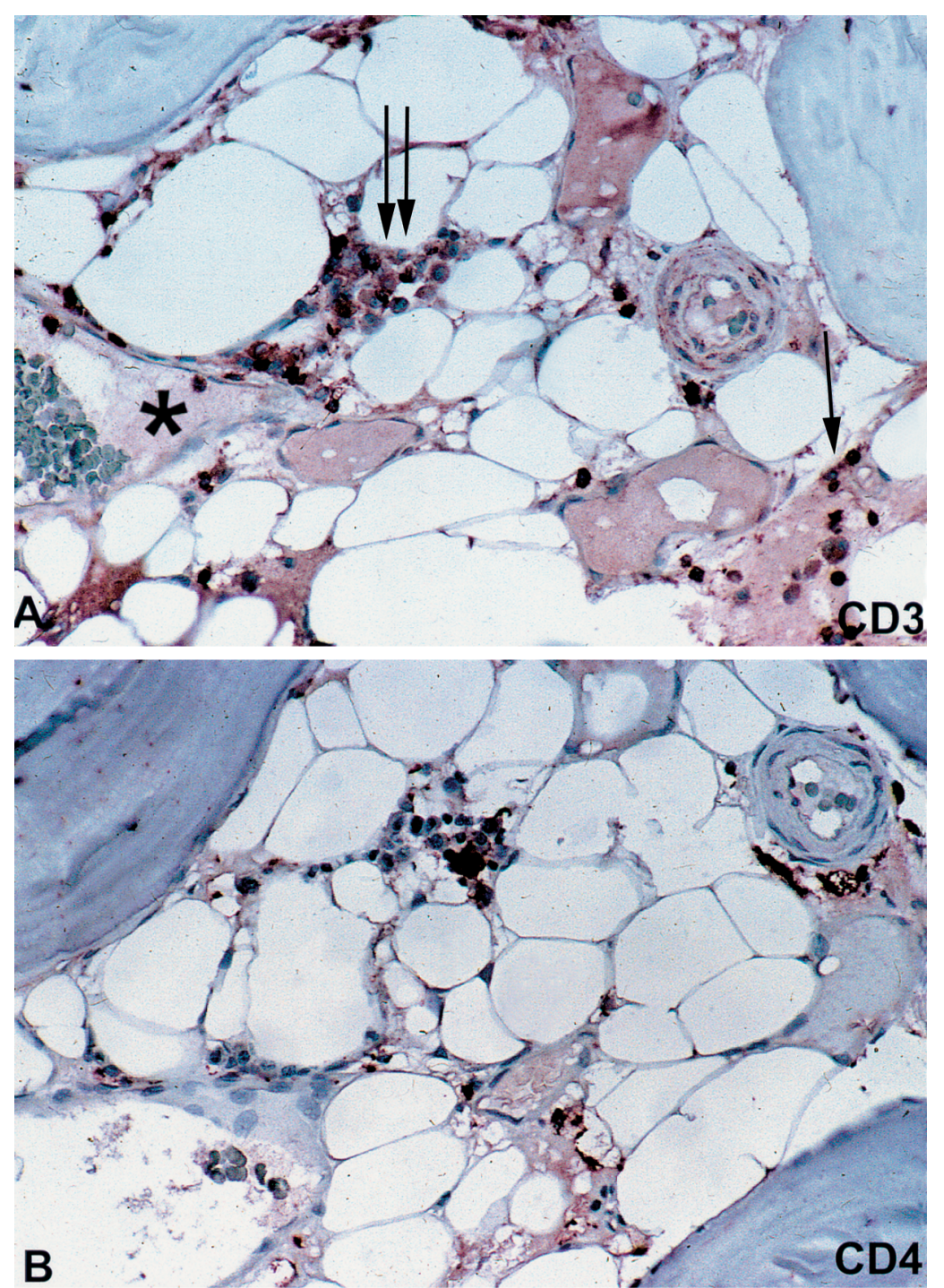

B

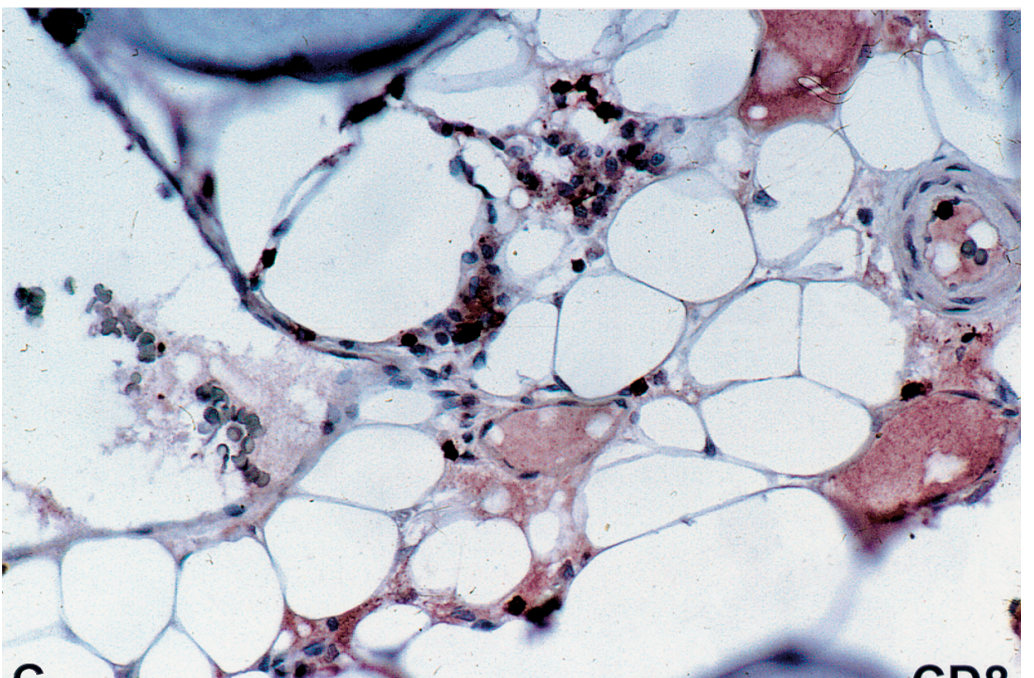

C $11 . \cos 35$ CD8

Figure 3 Serial immunohistochemistry sections of a cruciate ligament enthesis from a patient with ankylosing spondylitis (patient 4). (A) Anti-CD3+ antibody. Sparse (sing arrow) or nodular (double arrows) CD3+ cell infiltrates of the bone marrow around a congestive vascular sinus (*). (B and C) Anti-CD4 and anti-CD8 antibodies, respectively. The $C D 3+$ cell infiltrate contains both $C D 4+$ and $C D 8+$ cells, with an apparent cells, which was confirmed by thr magnification $\times 250$. active disease, and a standardised measurement of the disease activity was not available for each of them.

We thought it was important to compare our results in patients with $\mathrm{SpA}$ not only with patients with a degenerative disease, such as $\mathrm{OA}$, but also with patients with RA. Indeed, RA and $\mathrm{SpA}$ are the two main inflammatory rheumatic diseases, but they have different clinica and radiological aspects and different pathogenic mechanisms. In particular, differences in the cellular infiltrate of synovitis between RA and reactive arthritis (a subgroup of $\mathrm{SpA}$ ) have been recently reported, showing, among other results, more lymphocytes in RA. ${ }^{13}$ Conversely, in the entheses we found more lymphocytes and other signs of inflammation in SpA specimens than in RA specimens. This may support the view that the site of inflammation is different between $\mathrm{RA}$ and $\mathrm{SpA}$, being localised to the synovium in $\mathrm{RA}$ and to the entheses in $\mathrm{SpA}^{2}$

The predominance of the inflammation in the bony component of the SpA specimens is in line with previous histological studies reporting an early development of granulation tissue within subchondral areas. ${ }^{2-14}$ Furthermore, severe osteitis of the vertebral bodies ${ }^{15}$ and extensive bone marrow changes in the spine ${ }^{16}$ have also been reported in patients with $A$ More recently, the first studies using magnetic resonance imaging (MRI) with fat suppression resonance imaging (MRI) with fat suppression
sequences to investigate enthesitis in AS sequences to investigate enthesitis in AS showed extensive bone oedema. ${ }^{17}$ Our histo-
logical results are in keeping with these interesting MRI findings.

Lymphocytes were the main cell population of the inflammatory infiltrate in our SpA specimens. Previous studies also found a predominance of lymphocytes and plasma cells, but did not count these cell populations. ${ }^{2-18}$ A new piece of information provided by our study is that among these lymphocytes $\mathrm{T}$ cells were more abundant than $\mathrm{B}$ cells, and that among the T cells most were CD8+. It must be kept in mind that these results were obtained in mind that the resuls were obtair ongstanding SpA and may not apply to early nthesitis.

No previous data on cell populations in $\mathrm{SpA}$ entheses are available. However, studies of other tissues from patients with AS have been published. In a study of peripheral synovial membrane Cunnane et al recently reported a moderate predominance (1.6-fold) of CD4+ cells over CD8+ cells. ${ }^{4}$ Using semiquantitative analysis, Kidd et al noted that these two subsets were present in equal numbers. ${ }^{19}$ In fact, both were present in equal numbers. In fact, both of CD4+ cells, characteristic of rheumatoid synovium, ${ }^{20}$ was not a feature of AS synovitis. The only available study of cell infiltrates in sacroiliitis ${ }^{5}$ in AS found a predominance of

CD4+ cells, but here again the difference was modest $(30 \%$ of CD $4+v 16 \%$ of CD $8+$ cells). Thus these data and our results together support the hypothesis of a role for CD8+ cells in the pathogenesis of SpA. Some results obtained from the synovial fluid of either patients with psoriatic arthritis or reactive
arthritis are consonant with this possibility, ${ }^{21} 22$ though it should be noted that findings from 
synovial fluid may not reflect the cellular changes in the synovium

An interesting point is whether these data shed light on the pathogenesis of SpAs, which is still speculative. ${ }^{67}$ The strong association between SpAs and the HLA class I gene B27 suggests involvement of B27 restricted antigen suggests involvement of $\mathrm{B} 27$ restricted antigen
presentation to $\mathrm{CD} 8+$ cells, the antigen being presentation to CD8+ cells, the antigen being
either a bacterial antigen or a self antigen. However, other possibilities have been suggested. A recent hypothesis gives a key role to CD4+ cells. ${ }^{6}$ Our results may rather support a predominant role of CD8+ cells in the pathogenesis of the enthesis lesions seen in pathogenesis of the

In conclusion, oedema and inflammatory cell infiltrates were more marked in all eight $\mathrm{SpA}$ enthesis specimens than in the four RA and three OA specimens. In SpA, the infiltrates predominated clearly in the bone marrow in zone 4 of the entheses. They were composed primarily of $\mathrm{T}$ cells, among which the most primarily of $\mathrm{T}$ cells, among which the most abundant subset was CD8+. These results are
consistent with persistent inflammation of the consistent with persistent inflammation of the
bone marrow in zone 4 of SpA enthesopathy, mediated primarily by CD8+ cells. 1 Arnett FC. Seronegative spondylarthropathies. Bull Rheum
Dis 1987;37:1-12.
2 Ball J. Enthesopathy of rheumatoid and ankylosing spond2 Ball J. Enthesopathy of rheumatoid and ankylosing spond-
ylitis. Ann Rheum Dis 1971;30:213-23. ylitis. Ann Rheum Dis 1971;30:213-23.
McGonagle D, Khan MA, Marzo-Ortega H, O'Connor P,
Gibbon W, Emery P Enthesitis in spondyloarthropathy Gibbon W, Emery P. Enthesitis in spondyloarthropathy
Curr Opin Rheumatol 1999;11:244-50. Cunnane G, Breshnihan B, Fitzerald O. Immunohistologic
analysis of peripheral joint disease in ankylosing spondyli-
tis. Arthritis Rheum 1998;41:180-2.

5 Braun J, Bollow M, Neure L, Seipelt E, Seyrekbasan F, Herbst $\mathrm{H}$, et al. Use of imnunohistologic and in sit joint biopsy specimens from patients with ankylosing spondylitis. Arthritis Rheum 1995;38:499-505.

and T-cell JD, eds. The spondylarthritides. Oxford: Oxford University

Press, 1998:195-206.
Sieper S, Braun B. Pathogenesis of spondylarthropathies.
Persistent bacterial antigen autoimmunity or both? ArthriPersistent bacterial antigen, aus
tis Rheum 1995;38:1547-54.
8 Dougados M, Van Den Linden S, Juhlin R, Huitfeldt B Amor B, Calin A, et al. The European Spondylarthropathy Group preliminary criteria for the classification of spondyarthropathy. Arthritis Rheum 1991;34:1218-27.

9 Arnett FC, Edworthy SM, Bloch DA, McShane DJ, Frie tion 1987 revised criteria for the classifiction of Associatoid arthritis. Arthritis Rheum 1988;31:315-24.

0 Altman R, Asch E, Bloch D, Bole G, Borenstein D, Brand $\mathrm{K}$, et al. Development of criteria for the classification an reporting of osteo tis A, Sabatini E, et al. Antigen retrieval techniques immunohistochemistry: comparison of different methods.

Van Der Linden S, Valkent

, Valkenburg HA, Cats A. Evaluation of modification of the New York Criteria. Arthritis Rheun 1984;27:361-8

Smeets TJM, Dohlain RJEM, Breedveld FC, Tak PP. Analysis of the cellular infiltrates and expression of arthritis and reavial tissue from patients with rheumatoid 4 Shichikawa K, Tsuimoto M, Nishioko J, Nishibavashi atsumoto K. Histopathology of early sacroilitis an spondylitis. In: Ziff M, Cohen SB, Pearch. Vol 9. The spondylar thropathies. New York: Raven Press, 1985:15-24.

15 Aufdermaur M. Pathogenesis of square bodies in ankylosing spowley MID, Chalmen TM, Kellyen JH, Bing

tive lesions of vertebral bodies in ankylosing spondylitis. Ann Rheum Dis 1972;31:345-58. McGonagle D, Gibbon W, O'Connor P, Green M, Pease C Emery 1 . Characteristic magnetic resonance imaging Arthritis Rheum 1998;41:694-700.

De Parc JM. Etude anatomo-pathologique des enthésopathies des

9 Kidd BL, Moore K, Walters MT, Smith JL, Cawley MID. Immunohistological features of synovitis in ankylosing spondylitis: a comparison with rheumatoid arthritis. An

tological analysis of anossy G, Poulter LW. An immunohismicroenvironment in the synovial membranes of patient with rheumatoid arthritis using monoclonal antibodies.

Costello P, Breshnihan B, O'Farelly C, Fitzgerald $\mathrm{O}$
Predominance of CD8+ T lymphocytes in psoriatic arthri-

22 Allen RL, Gillespie GMA, Hall F, Edmonds S, Hall MA in the blood and al. Multiple $T$ cell expansions are foun arthritis. J Rheumatol 1997;24:1750-7. 